Regular Article

\title{
A two-angle model of dynamic wetting in microscale capillaries under low capillary numbers with experiments
}

\author{
Da Lei ${ }^{a}$, Mian Lin ${ }^{\mathrm{b}, \mathrm{c}, *}$, Yun $\mathrm{Li}^{\mathrm{a}, *}$, Wenbin Jiang ${ }^{\mathrm{b}}$ \\ a School of Chemical Engineering and Technology, Xi'an Jiaotong University, Xi'an, Shaanxi 710049, China \\ ${ }^{\mathrm{b}}$ Institute of Mechanics, Chinese Academy of Sciences, Beijing 100190, China \\ ${ }^{\mathrm{c}}$ School of Engineering Science, University of Chinese Academy of Sciences, Beijing 100049, China
}

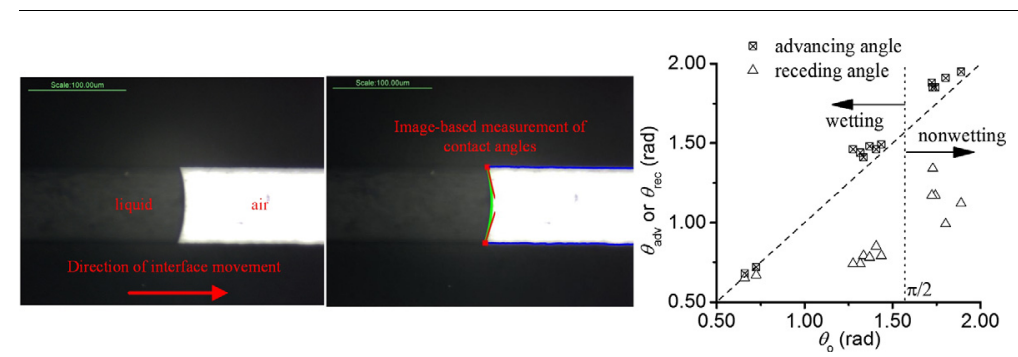

\section{A R T I C L E I N F O}

\section{Article history:}

Received 15 November 2017

Revised 27 February 2018

Accepted 27 February 2018

Available online 1 March 2018

\section{Keywords:}

Dynamic contact angle

Liquid-gas displacement

Microscale capillary

Wetting

Two-angle model

Contact angle hysteresis

\begin{abstract}
A B S T R A C T
Objectives: An accurate model of the dynamic contact angle $\theta_{d}$ is critical for the calculation of capillary force in applications like enhanced oil recovery, where the capillary number $C a$ ranges from $10^{-10}$ to $10^{-5}$ and the Bond number $B o$ is less than $10^{-4}$. The rate-dependence of the dynamic contact angle under such conditions remains blurred, and is the main target of this study.

Experiments: Featuring with pressure control and interface tracking, the innovative experimental system presented in this work achieves the desired ranges of $\mathrm{Ca}$ and $\mathrm{Bo}$, and enables the direct optical measurement of dynamic contact angles in capillaries as tiny as $40 \times 20$ (width $\times$ height) $\mu \mathrm{m}$ and $80 \times 20 \mu \mathrm{m}$. The advancing and receding processes of wetting and nonwetting liquids were tested.

Findings: The dynamic contact angle was confirmed velocity-independent with $10^{-9}<\mathrm{Ca}<10^{-5}$ (contact line velocity $V=0.135-490 \mu \mathrm{m} / \mathrm{s}$ ) and it can be described by a two-angle model with desirable accuracy. A modified two-angle model was developed and an empirical form was obtained from experiments. For different liquids contacting the same surface, the advancing angle $\theta_{a d v}$ approximately equals the static contact angle $\theta_{0}$. The receding angle $\theta_{\text {rec }}$ was found to be a linear function of $\theta_{a d v}$, in good agreement with our and other experiments from the literature.
\end{abstract}

(c) 2018 Elsevier Inc. All rights reserved.

\footnotetext{
* Corresponding authors at: Institute of Mechanics, Chinese Academy of Sciences, Beijing 100190, China (M. Lin), School of Chemical Engineering and Technology, Xi'an Jiaotong University, Xi'an, Shaanxi 710049, China (Y. Li).

E-mail addresses: linmian@imech.ac.cn (M. Lin), yunli@mail.xjtu.edu.cn (Y. Li).
}

\section{Introduction}

The liquid-gas displacement takes place in extracting oil from porous-type reservoirs by solution gas drive, water alternating gas injection or other enhanced oil recovery (EOR) schemes [14]. Understanding the mechanism of two-phase flow at pore scales is decisive for optimizing the EOR process, thus has attracted many theoretical and experimental researches during the past four dec- 
ades [5-9]. For most pore-level displacements, the capillary number $\mathrm{Ca}(\mathrm{Ca}=\mu \mathrm{V} / \gamma$, where $\mu$ is the viscosity of the liquid, $V$ the interface velocity and $\gamma$ the interfacial tension) in oil reservoirs ranges from $10^{-10}$ to $10^{-5}$, and the Bond number $B o\left(\rho g h^{2} / \gamma\right.$, where $\rho$ is the density of the liquid, $g$ the gravitational constant and $h$ the characteristic length of the flow) is less than $10^{-4}$, implying the capillarity dominates the movement of the liquid-gas interface $[3,10]$. This paper focuses on the wetting process in the mentioned scopes of $\mathrm{Ca}$ and $\mathrm{Bo}$.

Precise prediction of capillarity-dominated multiphase flow in porous systems relies on an accurate model of the contact angle in dynamic conditions [11]. Possible models of the dynamic contact angle $\theta_{d}$ can be categorized into two types, velocitydependent and two-angle models, as depicted in Fig. 1. The hydrodynamic model (HD) and molecular kinetic theory (MKT) are typical velocity-dependent models.

\subsection{Velocity-dependent models}

A simplification of the HD for a liquid-gas system was made by Voinov, given by Eq. (1) [12,13]:

$\left\{\begin{array}{cl}\theta_{d}^{3}=\theta_{a d v, \text { min }}^{3}+9 \operatorname{Caln}\left(\frac{L_{H}}{L_{S, a d v}}\right) & C a>0 \\ \theta_{d}^{3}=\theta_{r e c, \text { max }}^{3}+9 \operatorname{Caln}\left(\frac{L_{H}}{L_{S, \text { rec }}}\right) & C a<0\end{array}\right.$

where the sign of $\mathrm{Ca}$ represents the movement direction, positive $\mathrm{Ca}$ being advancing and negative $\mathrm{Ca}$ being receding. $\theta_{a d v, \min }$ and $\theta_{\text {rec, } \max }$ are the minimum contact angle during advancing and the maximum contact angle during receding, respectively. A slip length $L_{S}$ and a characteristic length $L_{\mathrm{H}}$ are introduced to characterize the three-phase contact zone, where the no-slip boundary condition fails $[13,14]$.

Another model describing the effect of velocity is the MKT, which assumes that energy dissipates at the contact line where liquid, gas and solid meet. And it is given by Eq. (2) $[15,16]$ :

$\cos \theta_{d}=\frac{\cos \theta_{a d v, \text { max }}+\cos \theta_{\text {rec, } \min }}{2}-\frac{2 k_{B} T}{\gamma \lambda^{2}} \operatorname{arsinh}\left(\frac{\gamma C a}{2 K_{0} \lambda \mu}\right)$

where $T$ stands for the absolute temperature, $k_{B}$ the Boltzmann constant, $\lambda$ the average distance of molecular displacement and $K_{0}$ the equilibrium frequency at which the molecules oscillates in the three-phase zone. $\theta_{a d v, \max }$ and $\theta_{\text {rec, } \min }$ are respectively the maximum and minimum angles for advancing and receding.

\subsection{Two-angle model}

When the velocity-dependence is negligible, the two angle model assumes that the dynamic contact angle $\theta_{d}$ can be repre-
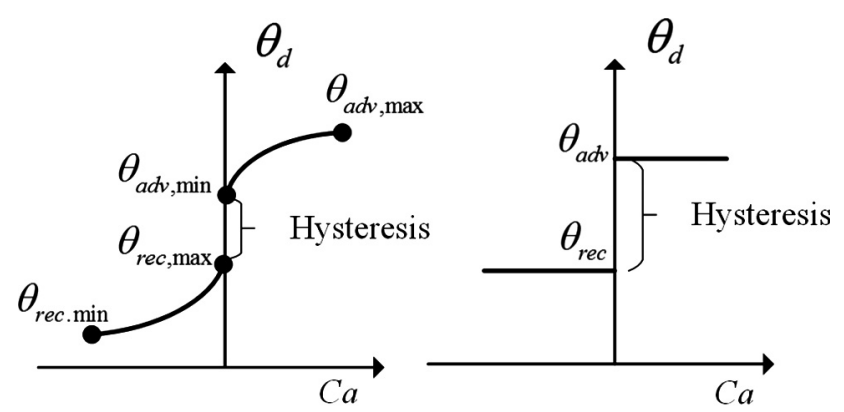

Velocity-dependent model

Two-angle model sented by $\theta_{a d v}$ and $\theta_{\text {rec }}$ respectively for advancing and receding, given by Eq. (3) [11],

$\left\{\begin{array}{cc}\theta_{d}=\theta_{a d v} & C a>0 \\ \theta_{d}=\theta_{\text {rec }} & C a<0\end{array}\right.$

Whether or not the $\theta_{d}$ is velocity-dependent remains unclear and none of the models have been confirmed to properly describe the dynamic contact angle with $10^{-10}<\mathrm{Ca}<10^{-5}$ and $\mathrm{Bo}<10^{-4}$. Despite a great deal of experiments have been reported, some of them confirm the dependence of velocity [13,17-21], while another portion reports the opposite conclusion [22-25]. Table 1 gives a brief summary of dynamic wetting experiments. Among various methods, the plate immersion method, also known as Wilhelmy plate method, measures the force exerted on a plate when the plate is vertically immersed in the liquid, and the contact angle can be calculated from the force [22]. For filament immersion and sessile drop method, the contact angle can be directly observed and measured $[13,24]$. In capillary flow method, the contact angle can either be directly observed or calculated from pressure data. Capillary rise experiments, however, measure the height of wetting liquids surface during imbibition and calculate the contact angle through flow dynamics [26]. Moreover, the mentioned models have been used in comparison with various wetting dynamics experiments rather than prediction of wetting behaviors in specific systems [11]. The reason is that large discrepancies lie in the HD and MKT parameters found in the literature, and unreasonable values are frequently obtained $[13,27]$. Simple as it may be, the two-angle model is not a correlation with the static contact angle $\theta_{0}$, thus has no prediction capability either. Further development of the two-angle model is required. In our work, the static contact angle is measured by the sessile drop method with a droplet volume of $2-3 \mu \mathrm{L}$, when the droplet is under static condition.

On one hand, the Bond number directly indicates the gravity effect. On the other hand, it implies the diameter of a capillary. To achieve $B o<10^{-4}$, the capillary diameter should be less than $0.03 \mathrm{~mm}$ (take water at room temperature as an example). Due to the limitation of observation methods, most capillary flow experiments were carried out in capillaries with a diameter near $1 \mathrm{~mm}[19,20,28]$. Without direct measurement of the contact angle, capillary rise experiments can utilize capillaries with a diameter ranging from 0.6 to $0.2 \mathrm{~mm}$, but the $\mathrm{Ca}$ cannot be controlled $[23,26,29,30]$. These shortcomings should be overcome to achieve expected ranges of $\mathrm{Ca}$ and $\mathrm{Bo}$.

This paper aims to clarify: 1 . Is the dynamic contact angle velocity-dependent under the condition of $10^{-10}<\mathrm{Ca}<10^{-5}$ and $B o<10^{-4}$ ? 2. What's the best model for the description of the dynamic contact angle under low capillary numbers.

In this work, a system was designed to enable the microscopic observation and tracking of a moving interface in a microscale capillary. Dynamic contact angles of a liquid/gas interface in channels as tiny as $40 \times 20$ (width $\times$ height) $\mu \mathrm{m}$ and $80 \times 20 \mu \mathrm{m}$ were measured by optical method for the first time. The advancing and receding processes of nonwetting and wetting liquids (deionized water, glycerol, etc.) were tested under $10^{-10} \leq \mathrm{Ca}<10^{-3}$ and $\mathrm{Bo}$ $<10^{-4}$. The system, experiment procedures and the error of measurement will be introduced in the first place. The dynamic contact angle was confirmed to be velocity-independent by experiments, and on this basis a modified two-angle model will be discussed which correlates the advancing and receding angles to the static angle. The model will be compared with our experiments along with others performed in different methods. The two-angle model could be a new solution to the calculation of capillary force in twophase flow in porous media.

Fig. 1. Possible models of the dynamic contact angle. 
Table 1

Examples of dynamic contact angle experiment.

\begin{tabular}{|c|c|c|c|c|c|c|c|}
\hline Reference & Test method & velocity $(\mathrm{mm} / \mathrm{min})$ & $\mathrm{Ca}^{\mathrm{a}}$ & $B o^{a}$ & $\begin{array}{l}\text { Capillary Diameter } \\
(\mathrm{mm})\end{array}$ & Circular tube & $\begin{array}{l}\text { Velocity } \\
\text { dependence }\end{array}$ \\
\hline Johnson et al. [22] & Plate immersion & $0.5-2.5$ & $2 \times 10^{-8}-5 \times 10^{-7}$ & $\sim$ & $\sim$ & $\sim$ & $\times$ \\
\hline Morrow and Nguyen [23] & Capillary flow & $0.012-12$ & $7 \times 10^{-8}-7 \times 10^{-5}$ & $>0.01$ & $0.3,0.7$ & レ & $x$ \\
\hline Kwok et al. [24] & Sessile drop & $0.01-1.2$ & $2 \times 10^{-9}-3 \times 10^{-7}$ & $\sim$ & $\sim$ & $\sim$ & $\times$ \\
\hline Cain et al.[25] & Sessile drop & 0.5528 & $1.3 \times 10^{-7}$ & $\sim$ & $\sim$ & $\sim$ & $\times$ \\
\hline Petrov et al. [13] & Filament immersion & $300-1200$ & $10^{-5}-6 \times 10^{-3}$ & $\sim$ & $\sim$ & $\sim$ & $\nu$ \\
\hline Schneemilch et al. [17] & Filament immersion & $300-1200$ & $6 \times 10^{-5}-3 \times 10^{-3}$ & $\sim$ & $\sim$ & $\sim$ & $\nu$ \\
\hline Ström et al. [18] & Plate immersion & $0.18-10$ & $10^{-7}-10^{-2}$ & $\sim$ & $\sim$ & $\sim$ & $\nu$ \\
\hline Rose and Heins [19] & Capillary flow & $3-144$ & $7 \times 10^{-5}-7 \times 10^{-3}$ & $>0.01$ & $0.3,0.5$ & レ & $\nu$ \\
\hline Hoffman and Richard [20] & Capillary flow & $0.006-6$ & $4 \times 10^{-5}-36$ & 0.6 & 1.96 & レ & $\nu$ \\
\hline Kim et al. [21] & Plate immersion & $12-1200$ & $10^{-5}-0.3$ & $\sim$ & $\sim$ & $\sim$ & $\nu$ \\
\hline
\end{tabular}

${ }^{\text {a }}$ Calculated by properties of water at room temperature if not provided in the reference

\section{Experimental set-up}

\subsection{Facilities and materials}

Microchannels fabricated in a polydimethylsiloxane (PDMS) chip are all $20 \mu \mathrm{m}$ in height, with widths of 40 and $80 \mu \mathrm{m}$, and lengths of 10 and $20 \mathrm{~mm}$. The PDMS chip is horizontally mounted on a stage driven by a stepping motor. Receiving electrical signals from Data Acquisition (DAQ) chip (National Instrument USB-6001), the motorized stage moves accurately at speed ranging from 0.001 to $0.773 \mathrm{~mm} / \mathrm{s}$. To observe the contact angle at large magnifications while the contact line is moving and the microscope is static, the motorized stage moves in the opposite direction of the displacement, as is shown in Fig. 2. The microscope (Beijing Cewei) is configured with a fixed focus objective lens with magnification of 20. Feeding back real-time images to the computer screen. A 1600 mega-pixel CMOS captures images in 24-bit RGB format and its resolution is $0.135 \mu \mathrm{m} / \mathrm{pixel}$.

The liquid is driven by a syringe pump (Longer Pump TS-1B) and injected through the piping system, eventually into the horizontal microchannel. A pressure transducer is mounted in a $T$ connector measuring the fluid pressure at the micro tube inlet up to $20 \mathrm{kPa}$ with an accuracy of $0.1 \%$ full scale. The combination of a pressure transducer, a syringe pump and computer programs are equivalent to a closed-loop control system, achieving a constant pressure injection with fluctuation less than $1 \%$ of the given pressure.

PDMS is a transparent, viscoelastic material frequently used for microfluidics experiments [31,32]. The PDMS chip was manufactured by the Micro-System Lab of CapitalBio Corporation, Beijing.

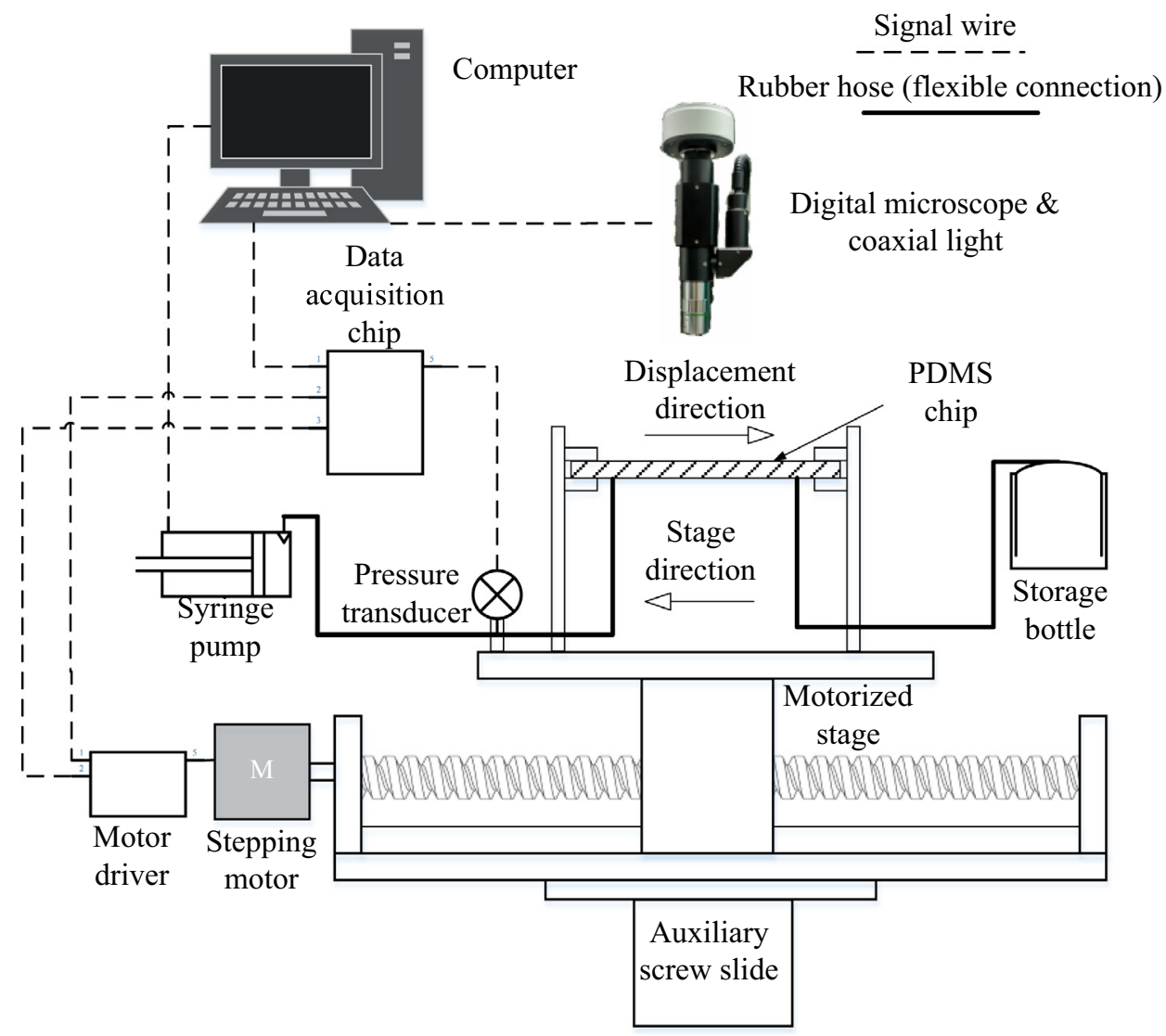

Fig.2. The layout of experimental apparatus. 
The roof of the chamber tends to collapse and block the flow where the ratio between the width and the height is large [33]. Therefore, apart from the main body of a microchannel, pillars are designed to support the inlet and outlet zone [32], as demonstrated in Fig. 3. Details of fabrication of a PDMS chip can be found in an article from Karadimitrou [32] and references therein.

Special attentions should be paid to the liquid selection because some organic liquids may induce swelling in PDMS [32,34]. To ensure that the test liquids possess no swelling effect, samples of PDMS were immersed in liquids for more than $12 \mathrm{~h}$, then cleaned and dried. Next, dried samples were weighed and the surface free energy was measured. Samples' original surface free energy was $21.27 \pm 0.56 \mathrm{mN} / \mathrm{m}$, with disperse part $21.15 \pm 0.47 \mathrm{mN} / \mathrm{m}$ and polar part $0.12 \pm 0.09 \mathrm{mN} / \mathrm{m}$. The liquid is acceptable if the changes in sample weight, surface free energy and its disperse part before and after immersion are less than 5\%. All liquids tested are listed in Table 2. Interfacial tension, static contact angle and surface free energy were measured with a drop shape analyzer (Krüss DSA100). Viscosities were measured using a digital rotary viscometer. All reagents were purchased from Sinopharm Chemical Reagent. Experiments were conducted under $28 \pm 1^{\circ} \mathrm{C}$ room temperature.

\subsection{Experiment procedures}

The syringe pump pushes the liquid into the PDMS chip where the liquid will firstly fill up the inlet zone and then enter the microchannel. Next the liquid-gas interface will be stabilized near the entrance to the tube. Note that to stabilize a nonwetting liquid, the pressure in the inlet zone should be controlled at a suitable positive value. To pull up a wetting liquid that tends to spontaneously enter the tube, negative pressure is needed in the inlet zone. Quick adjustment of the pressure calls for utilization of the fast-forward and fast-backward functions of the syringe pump, along with close attention to the reading of the pressure sensor.

To initiate the advancing of the interface, the syringe pump can start pushing in three ways: fast-forward, injecting at a given flow rate or injecting at a given pressure. Hence, a wetting or nonwetting liquid will speed up from the entrance and pass through the tube. After the advancing finishes, the syringe pump will start extraction and initiate the receding process. As sketched in Fig. 2, most components are mounted on the stage, and the syringe pump is connected to the pipe system with a rubber hose. This flexible connection ensures that the motorized stage does not interfere with the injection or any measurement mentioned above.

\subsection{Image-based measurement}

Images obtained from liquid-air experiments are of high contrast, with dark area marking liquid and PDMS itself, bright area marking air. They are firstly converted to a 256-level gray scale format. Then removing noise and threshold segmentation are imposed on each image, and turned original images into binary ones. Afterwards, boundaries are extracted from binary images where tube walls and the meniscus are identified and distinguished. Finally, the extracted interface is fitted by cubic polynomial and contact angles are computed at the contact points. The above process is briefly demonstrated in Fig. 4.

Normally, extracted contact points are precisely located at the tube wall according to the methods mentioned above. But strong-wetting liquids including paraffin oil and 1-propanol tend to spontaneously advance (imbibe) in micro tubes and a precursor film transport phenomenon was observed in advancing, as shown

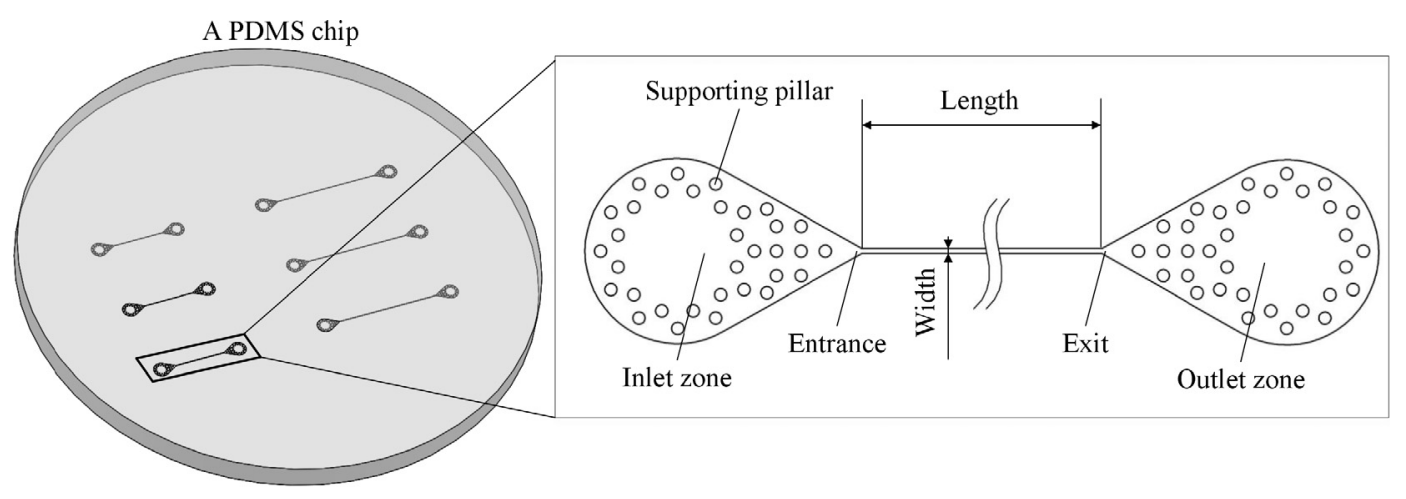

Fig. 3. The structure of a PDMS chip.

Table 2

Properties of tested liquids.

\begin{tabular}{|c|c|c|c|c|}
\hline Liquid (abbreviation) & Liquid viscosity $\mu$ (mPa.s) & Surface tension $\gamma(\mathrm{mN} / \mathrm{m})$ & Static contact angle $\theta_{o}$ (degree) & Density $\rho\left(\mathrm{kg} / \mathrm{m}^{3}\right)$ \\
\hline Water & $0.8407^{\mathrm{a}}$ & $69.59 \pm 0.78$ & $108.3 \pm 3.0$ & 996.21 \\
\hline 1-propanol & $1.959^{\mathrm{b}}$ & $23.09 \pm 0.43$ & $37.8 \pm 1.4$ & 803.85 \\
\hline $80 \%$ wt aqueous glycerol ( $80 \% A G)$ & $39.1^{\mathrm{a}}$ & $63.11 \pm 0.55$ & $99.9 \pm 1.6$ & 1193.0 \\
\hline $90 \%$ wt aqueous glycerol ( $90 \% A G)$ & $131.0^{\mathrm{b}}$ & $62.79 \pm 1.97$ & $99.0 \pm 1.5$ & 1223.2 \\
\hline Glycerol & $771.6^{\mathrm{b}}$ & $61.58 \pm 0.55$ & $98.7 \pm 0.9$ & 1255.0 \\
\hline Diethylene glycol (DEG) & 27 & $44.00 \pm 0.35$ & $80.6 \pm 1.9$ & 1116.5 \\
\hline Triethylene glycol (TEG) & 34 & $46.17 \pm 0.16$ & $82.3 \pm 2.8$ & 1122.5 \\
\hline Polyethylene glycol 300 (PEG300) & 67 & $44.35 \pm 0.08$ & $76.5 \pm 3.3$ & 1130 \\
\hline Paraffin oil & 18 & $25.17 \pm 0.63$ & $41.5 \pm 2.1$ & 843.5 \\
\hline Polyethylene glycol 200 (PEG200) & 42 & $50.82 \pm 2.18$ & $78.5 \pm 1.3$ & 1124 \\
\hline Polyethylene glycol 400 (PEG400) & 87 & $49.51 \pm 1.41$ & $75.4 \pm 1.5$ & 1130 \\
\hline Polyethylene glycol 600 (PEG600) & 114 & $51.72 \pm 1.36$ & $73.1 \pm 0.8$ & 1130 \\
\hline
\end{tabular}

\footnotetext{
a Interpolated at $28^{\circ} \mathrm{C}$ by the data from ref. [35].
}

b Measured at $25^{\circ} \mathrm{C}$, ref. [36]. 


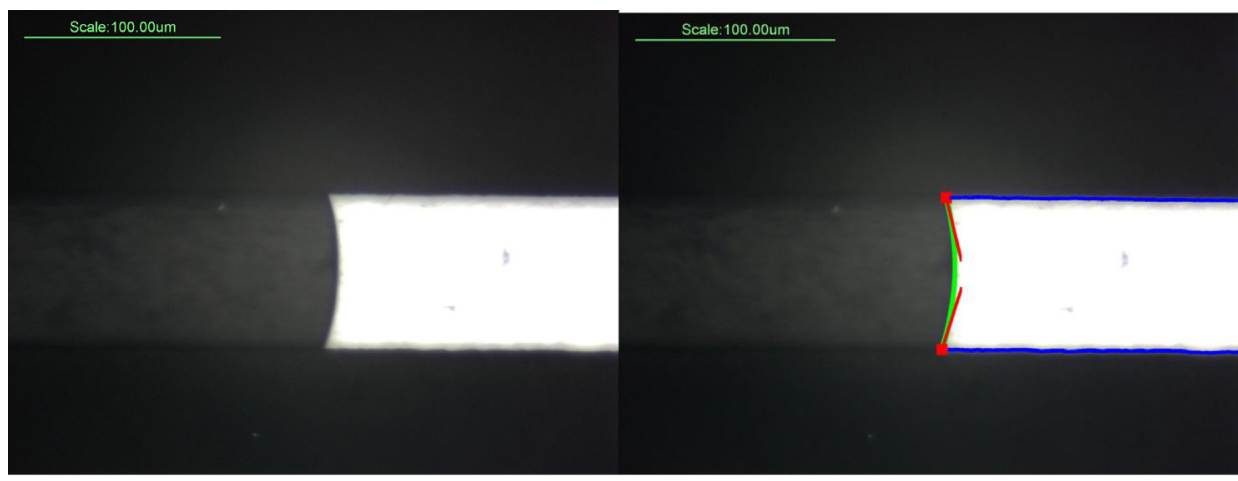

(a)

(b)

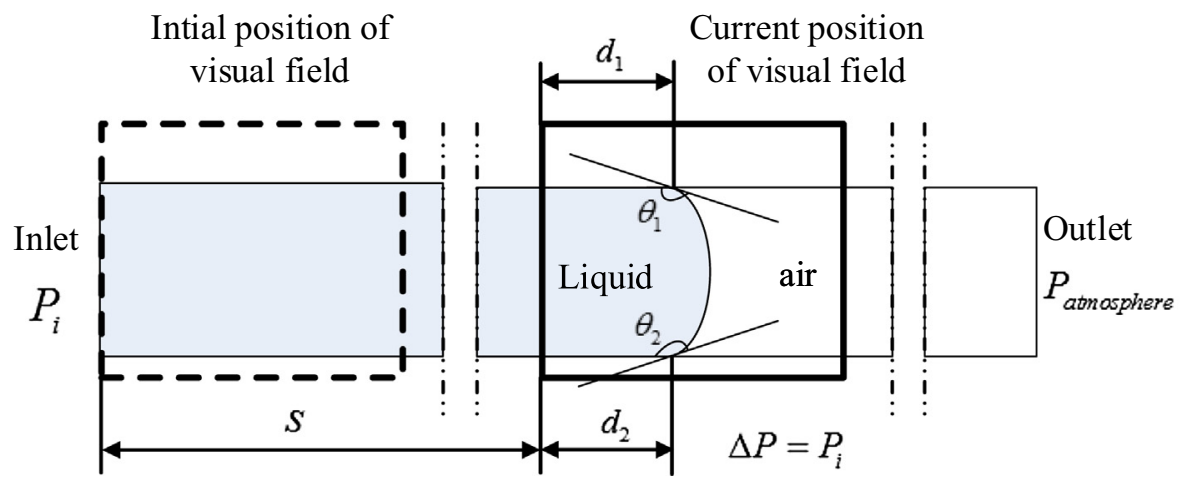

(c)

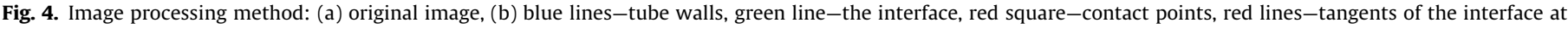

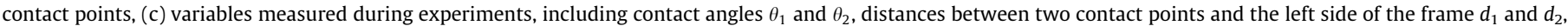
the displacement of motorized stage $s$, and the pressure at the inlet $P_{i}$. Because the outlet is directly connected to the atmosphere, the total pressure drop is $\Delta P=P_{i}$.

in Fig. 5. When they recede, dewetting films was formed on the tube walls.

A possible and related explanation for the liquid films is the MS$P$ theory. For a $n$-sided tube, the theory concludes that the wetting liquid will be left in the corner and form arc menisci during drainage (receding). And during imbibition (advancing), arc menisci will enlarge and advance into the center of the tube, when the contact angle $\theta<\pi / 2-\alpha$, wherein $\alpha$ is the half angle of corners [37]. For a retangular cross section, $\alpha=\pi / 4$. The critical contact angle is $\pi / 4$ for rectangular tube, and the static contact angle of 1-propanol and paraffin oil are 0.66 and $0.72 \mathrm{rad}$, well below $\pi / 4$. This indicates that 1-propanol and paraffin oil have the tendency to occupy the center of tube from the corners. Other wetting liquids whose static contact angles are over $\pi / 4$, do not have "liquid films". However, the MS-P theory only explain under what situation the equilibrium of existed arc menisci will be broken. In our experiments, we observed not only the "liquid films", but also its motions. We believe the wetting liquid firstly enters the corner and then spreads in the cross section as predicted by the MS-P theory.

The existence of the liquid film causes contact angles to be measured at a distance from the tube walls. Average thicknesses of 1propanol and paraffin's precursor film are respectively $6.2 \mu \mathrm{m}$ and $7.0 \mu \mathrm{m}$. Neither the precursor film nor the dewetting film is the subject of this research. However, they influence the contact points' location and contact angles measurement. More discussions about the liquid film can be found in references $[37,38]$.

All variables that need recording are demonstrated in Fig. 4 (c). The speed $V_{m}$ of the motorized stage is recorded every $25 \mathrm{~ms}$. The distance between the contact line and the left side of a frame is calculated as $d=\left(d_{1}+d_{2}\right) / 2$. By integrating the speed $V_{m}$ and an interval $\Delta t=25 \mathrm{~ms}$, the displacement $s$ that the motorized stage travels within time $t$ can be calculated as $s=\int_{0}^{t} V_{m}(t) d t \approx \sum i=$ $0 n V_{m}(i \Delta t) \Delta t$, wherein $i=1,2,3 \ldots n$ and $t=n \Delta t$. Starting from the channel entrance, the contact line displacement $x$ is calculated by $x(t)=s+d=\sum i=0 n V_{m} \Delta t+\left(d_{1}+d_{2}\right) / 2$.

\subsection{Error analysis}

The interface velocity $V$ is computed by $\frac{d x}{d t}$. $x(t)$ is indeed an array of displacement data $x_{j}$ corresponding to an array of time $t_{j}, j=$ $1,2,3 \ldots m$, in accordance to selected images. Therefore $\frac{d x}{d t}$ is computed by the finite difference method,

$V(t)=\frac{d x(t)}{d t} \Rightarrow V_{j}= \begin{cases}\frac{x_{j+1}-x_{j-1}}{t_{i+1}-t_{i-1}} & j=2,3 \ldots m-1 \\ \frac{x_{2}-x_{1}}{t_{2}-t_{1}} & j=1 \\ \frac{x_{m}-x_{m-1}}{t_{m}-t_{m-1}} & j=m\end{cases}$

Except for the head and tail of the data array, the majority of the data is calculated using a central difference method, which has second order accuracy. Here we focus on the uncertainty transferred by the velocity computation. The uncertainty of stage movement is $|\Delta s| / s=0.06 \%$, obtained by mounting a micro calibration slide on the stage and applying the image-based measurement. The accuracy of the interface position is $0.135 \mu \mathrm{m} /$ pixel which gives $|\Delta d|=0.135 \mu \mathrm{m}$. The uncertainty of $V$ computed by central difference is given by Eq. (5),

$\left|\Delta V_{j}\right|=\frac{\left|\Delta x_{j+1}\right|+\left|\Delta x_{j-1}\right|}{t_{j+1}-t_{j-1}}$ 


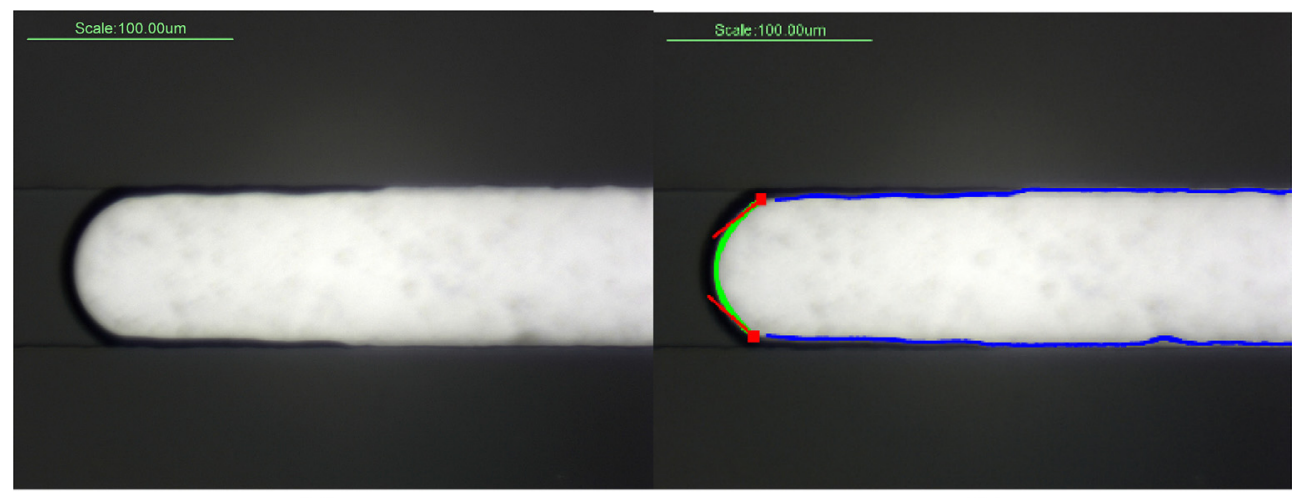

(a)

(b)

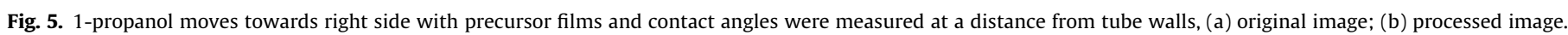

wherein $j=2,3 \ldots m-1$ and the minimum time interval is $1 \mathrm{~s}$, $t_{j+1}-t_{j-1} \geqslant 2 \mathrm{~s}$. When the interface moves at extremely low speed, i.e. the motorized stage do not need to operate and $|\Delta x|=|\Delta d|$; when the stage is motivated $|\Delta x|=|\Delta s|+|\Delta d|$, we have $|\Delta x|=0.06 \% s+|\Delta d| \leqslant 0.06 \% x+|\Delta d|$. According to this, an average relative error of $4.94 \%$ in the range of $0.135-490 \mu \mathrm{m} / \mathrm{s}$ is given by analyzing 50,896 measured points with Eq. (5).

The image-based measurement of contact angles is based on that the polynomial fitting has an advantage in handling asymmetric interface, and its deviation can be less than $0.7^{\circ}$ compared with the axisymmetric drop shape analysis-profile method [39]. We apply our image measurement method to sessile drop images analyzed by the drop shape analyzer Krüss DSA100. Good agreement is obtained and errors are less than $0.6^{\circ}$ and $0.5^{\circ}$ respectively for $\theta<$ $40^{\circ}$ and $40^{\circ}<\theta<120^{\circ}$. The relative error of viscosities and surface tensions measurement are $2.0 \%$ and $1.0 \%$ respectively. Capillary flow experiments for a single liquid was repeated in 2-3 different channels and 5-10 times in each channel to make sure the data were reproducible. More than 50,000 images were finally acquired and processed by our in-house source codes. Graphs with $\left|\theta_{1}-\theta_{2}\right|$ $<3^{\circ}$ were chosen for analysis. Moreover, the distance between two contact points should be approximately the tube width, with a maximum relative error of $10 \%$ in a selected graph. But for wetting liquids, the error threshold rises due to the existence of liquid films.

\section{Results and discussion}

\subsection{Comparison with velocity-dependent models}

The velocity-dependence of the dynamic contact angle will be firstly discussed. Experiments were fitted by the HD and MKT to see if they could adequately describe the dynamic contact angle under low capillary number. Parameters that need discussion are listed in Table 2. The fitting plots are demonstrated in Fig. 6 in part, since all plots are similar. Complete information of data fitting and plots of all liquids is given in Appendix A.

\subsubsection{Hydrodynamic model}

For a micro channel with a width of $80 \mu \mathrm{m}, L_{H}$ can be taken as the hydraulic radius $\left(w_{t} h_{t} /\left(2 w_{t}+2 h_{t}\right)\right.$, tube width $w_{t}$, tube height $h_{t}$ ) of $8 \mu \mathrm{m}$. For low capillary numbers, like $C a \sim 10^{-6}, \ln \left(L_{H} / L_{S}\right)$ needs to be around $10^{3}$ to bring about variation of $0.1 \mathrm{rad}$ in $\theta_{d}$ according to Eq. (1). $\ln \left(L_{H} / L_{S, \text { adv }}\right)>100$ and $\ln \left(L_{H} / L_{S, \text { rec }}\right)>100$ are obtained for most liquids meaning $L_{H} / L_{S} \sim+\infty$ and $L_{S} \approx 0$. This violates the "slip" boundary condition of the hydrodynamic model [14]. $L_{S}<10^{-20} \mu \mathrm{m}$ is marked as $L_{S}=0$ in Table 3 . The uncertainty
(95\% confidence bounds) is larger than the $L_{S}$ by several orders of magnitude, indicating the value is unacceptable. In Petrov's experiments, the fit of hydrodynamic model started from ${ }_{|\mathrm{Ca}| \mathrm{min}} \approx 2.5 \times$ $10^{-3}$ and $L_{S}$ for different liquids ranges from $5.3 \times 10^{-21}$ to $1.3 \times$ $10^{-9} \mathrm{~m}$ with $\mathrm{Ca}>2.0 \times 10^{-3}[13]$. The HD does not apply well to the experiments presented here, with $\mathrm{Ca}<10^{-3}$. The fitting results of $\theta_{a d v, \text { min }}$ and $\theta_{\text {rec,max }}$ can be found in Appendix A.

\subsubsection{Molecular kinetic theory}

Fitting constraints for the MKT are $\lambda>0, K_{0}>0$. The fitted uncertainties of $\lambda$ are well below $30 \%$ except for the $\lambda$ of 1 propanol and paraffin, uncertainties of which are respectively $217 \%$ and $38 \%$. In contrast, the $K_{0}$ presents tremendous uncertainty, indicating it is a weak parameter for data fitting. In Petrov's experiments, the $\lambda$ ranges from $4.2 \mathrm{~nm}$ to $5.9 \mathrm{~nm}$ with $10^{-5}<\mathrm{Ca}<$ $10^{-2}$ [13]. The fitted $\lambda$ from our experiments varies from $4.55 \times$ $10^{-3} \mathrm{~nm}$ to $2.37 \mathrm{~nm}$. The $K_{0}$ distributes from $1.79 \times 10^{-8}$ to $3928 \mathrm{~Hz}$ while the oscillation frequency less than $1 \mathrm{~Hz}$ is rare in literature $[13,27]$. Sub-atomic values of the $\lambda$ are obtained except for water and 1-propanol, demonstrating inconsistency with the model assumption.

\subsection{Independence of velocity}

The velocity-dependence of dynamic contact angles is weak, seen from Fig. 6, and the root mean square errors of two-angle fitting are less than 0.1 rad for all liquids. Similar results were obtained by other experiments. Johnson et al. measured the dynamic contact angles of different liquids on different surfaces by plate method, and found "the effect of velocity is zero or small" [22]. Morrow et al. also confirmed the velocity-independence of contact angles in their capillary rise experiments [23]. Sessile drop experiments also provide evidence of velocity-independence. Kwok et al. in their sessile drop experiments measured advancing contact angles of seven liquids at low rate $(0.01-1.2 \mathrm{~mm} / \mathrm{min})$ and obtained the same results that advancing angles are independent of velocity [24]. The constancy of advancing angles in slow motion can also be found in other sessile drop experiments carried out by Cain $(0.5528 \mathrm{~mm} / \mathrm{min}$ in Cain's) [25] .Our experiments are conducted under velocity ranges from 0.008 to $24 \mathrm{~mm} / \mathrm{min}$ which covers the range of mentioned experiments, and 11 out of 12 liquids were tested with $\mathrm{Ca}<10^{-4}$ in our experiments.

However, large portions of experiments also observed obvious effect of interface velocity [13,17-21], as listed in Table 1 . It can be noted that most experiments confirming velocity-dependence are conducted with $\mathrm{Ca}>10^{-5}$ or higher, while those supporting velocity-independence are carried out with $\mathrm{Ca}<10^{-5}$ or lower. 

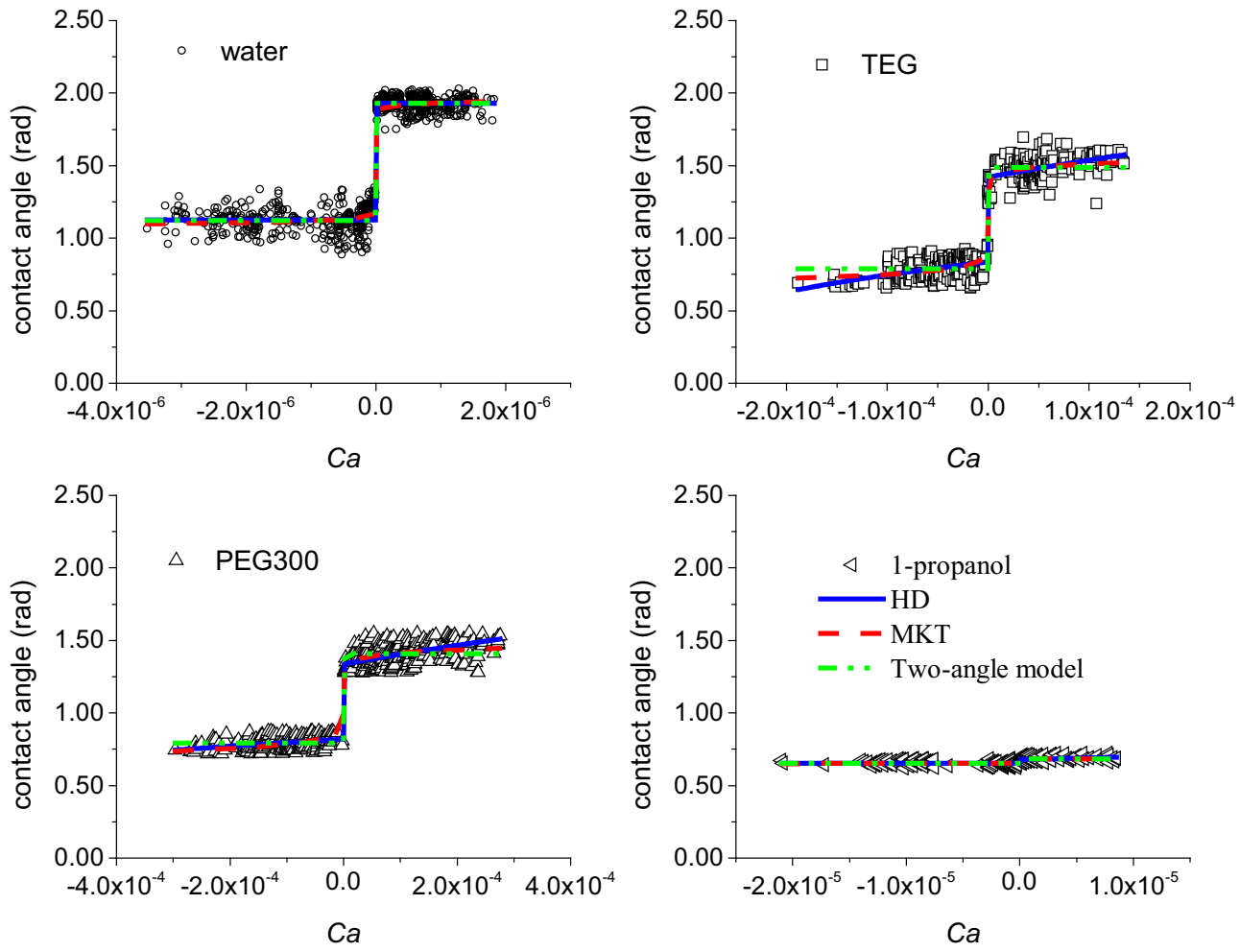

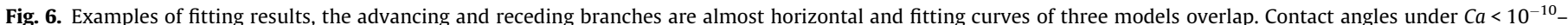
$10^{-9}$ are regarded as meta-stable and taken away in data fitting. Plots of the rest liquids can be found in Appendix A.

Table 3

Fitted parameters of the HD and MKT with 95\% confidence bounds.

\begin{tabular}{|c|c|c|c|c|}
\hline Liquid & $L_{S, a d v}(\mu \mathrm{m})$ & $L_{S, \text { rec }}(\mu \mathrm{m})$ & $\lambda(\mathrm{nm})$ & $K_{0}(\mathrm{~Hz})$ \\
\hline Water & $8 \pm 66520$ & $8 \pm 27063$ & $(7.70 \pm 2.36) \times 10^{-3}$ & $(8.89 \pm 320) \times 10^{-5}$ \\
\hline 1-propanol & 0 & $8 \pm 592$ & $0.88 \pm 1.95$ & $(3.86 \pm 416) \times 10^{-6}$ \\
\hline $80 \% A G$ & 0 & 0 & $(4.68 \pm 1.15) \times 10^{-3}$ & $43 \pm 123$ \\
\hline $90 \% A G$ & 0 & 0 & $(5.93 \pm 2.34) \times 10^{-3}$ & $35 \pm 162$ \\
\hline Glycerol & $(1.8 \pm 18) \times 10^{-15}$ & $(2.7 \pm 32) \times 10^{-3}$ & $(7.46 \pm 2.66) \times 10^{-3}$ & $0.028 \pm 0.195$ \\
\hline DEG & $8 \pm 1880$ & 0 & $(1.74 \pm 0.50) \times 10^{-2}$ & $(1.64 \pm 15.30) \times 10^{-5}$ \\
\hline TEG & 0 & 0 & $(6.49 \pm 1.14) \times 10^{-3}$ & $226 \pm 116$ \\
\hline PEG300 & 0 & 0 & $(6.22 \pm 0.92) \times 10^{-3}$ & $1135 \pm 1511$ \\
\hline Paraffin oil & 0 & $(1.5 \pm 81) \times 10^{-1}$ & $(7.07 \pm 2.93) \times 10^{-2}$ & $3928 \pm 6710$ \\
\hline PEG200 & 0 & $(2.2 \pm 87) \times 10^{-9}$ & $1.27 \pm 0.56 \times 10^{-2}$ & $1.69 \pm 62 \times 10^{-4}$ \\
\hline PEG400 & 0 & $1.1 \pm 28$ & $(1.20 \pm 0.45) \times 10^{-2}$ & $(2.4 \pm 20) \times 10^{-3}$ \\
\hline PEG600 & 0 & $(1.5 \pm 23) \times 10^{-11}$ & $(6.73 \pm 1.48) \times 10^{-3}$ & $25 \pm 71$ \\
\hline
\end{tabular}

Contact line velocity or viscous effect may induce significant changes in dynamic contact angles in high $\mathrm{Ca}$ regions, but its influence is subtle in low Ca regions. Thus, the two conclusions in literatures do not contradict each other and together they disclose in what $\mathrm{Ca}$ regions the velocity-dependence of the dynamic contact angle becomes significant. Here according to our experiments, a conservative estimate is that the dynamic contact angle is velocity-independent when $C a<10^{-5}$. In low $C a$ and $B o$ regions, it is interfacial interactions that control the shape of three-phase line and the contact angle, not the viscous force nor gravity.

\subsection{A modified two-angle model}

Since the dynamic contact angle becomes less velocitydependent, a two-angle model is enough to describe the relationship of $\theta_{d} / \mathrm{Ca}$ in low capillary numbers with desirable accuracy. Based on our experimental observation and comparisons with other experiments, a modification of the two-angle model is proposed.

\subsubsection{Assumptions}

Based on Young's theory, the static contact angle $\theta_{o}$ is a critical parameter characterizing the wettability of a three-phase (liquidgas-solid or liquid-liquid-solid) system, which is commonly measured by sessile drop method, where a liquid droplet is at equilibrium upon a solid plate [27,40-42]. Usually, meta-stable static contact angles are observed in experiments and vary from $\theta_{\text {rec }}$ to $\theta_{a d v}$, wherein $\theta_{\text {rec }} \leqslant \theta_{a d v}$. This phenomenon is known as contact angle hysteresis and can be expressed as the difference between the two boundaries:

$\Delta \theta_{\text {hys }}=\theta_{a d v}-\theta_{\text {rec }}$

The two-angle model can be further improved by linking to the fundamental parameter $\theta_{0}$. Here we propose that the $\Delta \theta_{\text {hys }}$ can be expressed by functions of the $\theta_{0}$ and two assumptions are made: 
(i) the contact angle hysteresis vanishes when a liquid drop can spread out $\left(\theta_{o}=0\right)$ on the solid surface; (ii) the $\Delta \theta_{\text {hys }}$ increases linearly with the $\theta_{0}$. These assumptions are given in Eq. (7).

$\left\{\begin{array}{c}\Delta \theta_{\text {hys }} \mid \theta_{0}=0=0 \\ \frac{\partial\left(\Delta \theta_{\text {hys }}\right)}{\partial \theta_{0}}=k>0\end{array}\right.$

The first assumption is based on the fundamental fact that, the liquid drop becomes a liquid film adhering to the solid surface when $\theta_{0}=0$. At such a static condition, the three-phase contact point goes infinitely far, and the advancing or receding of the contact point will not happen. Surely the difference between the two processes does not exist. The second assumption is based on experimental observations including the present and other experiments.

A simple form of the mentioned linear relationship between the $\Delta \theta_{\text {hys }}$ and the $\theta_{0}$ is given by,

$\Delta \theta_{\text {hys }}=k \theta_{0} \Rightarrow \theta_{\text {adv }}-\theta_{\text {rec }}=k \theta_{0}$

wherein $k$ characterizes the solid surfaces and remains constant for different liquid. Combining Eqs. (6) and (8), the two-angle model in Eq. (3) can be rewritten as,

$\begin{cases}\theta_{d}=\theta_{a d v} & C a>0 \\ \theta_{d}=\theta_{a d v}-k \theta_{0} & C a<0\end{cases}$

Considering the nature that the $\Delta \theta_{\text {hys }}$ will not be greater than the $\theta_{0}$, we have $0<k \leqslant 1$. To validate the modified tow-anlge model, Eq. (8) needs to be validated by our experiments and those found in literatures.

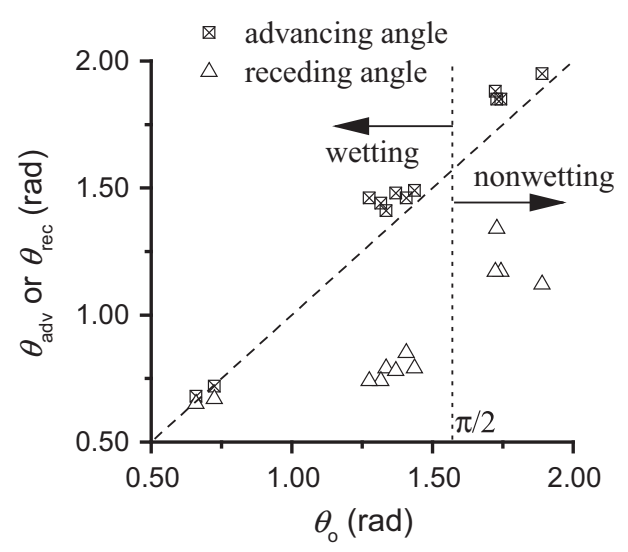

Fig. 7. The fitted advancing and receding angles of the two-angle model. It's obvious that advancing angles are close to static contact angles but receding angles deviate from static contact angles significantly.

\subsubsection{Advancing and receding angles}

Advancing angles are close to the static contact angle $\theta_{0}$ for both wetting and nonwetting liquids, but the receding angles differ significantly from the $\theta_{o}$ except for paraffin and 1-propanol, as shown in Fig. 7.

The deviation of $\theta_{a d v}$ from $\theta_{0}$ for all fluids are less than $15 \%$ but the deviation of $\theta_{\text {rec }}$ reaches over $15 \%$ and peaks at $44.4 \%$ for $20 \% \mathrm{wt}$ aqueous glycerol, except for 1-propanol and paraffin. Relevant results are listed in Table 4. Taking out PEG600, the deviations of $\theta_{a d v}$ are basically less than $10 \%$.

We ascribe the coincidence between the $\theta_{a d v}$ and $\theta_{0}$ to the sessile drop experiments, where a liquid drop is inevitably influenced by gravitation and on the verge of spreading (advancing). Our static contact angles are measured using sessile drop method (Krüss DSA100 drop shape analyzer), with droplet volumes of 2-3 $\mu \mathrm{L}$. Normally the droplet volume is around milliliters and the height is around $1 \mathrm{~mm}$ or more [24,42,43], leading to Bond numbers on the order of $0.1-1$. Hence the effect of gravity cannot be ignored. Same phenomena are observed in other experiments where the $\theta_{\text {ad } v}$ are close to the $\theta_{0}$ while the deviation of $\theta_{\text {rec }}$ is significant [44]. With the experimental observation $\theta_{a d v} \approx \theta_{0}$, Eq. (8) can be further reduced by replacing $\theta_{o}$ by $\theta_{a d v}$ and ignoring the approximation,

$\theta_{\text {rec }}=(1-k) \theta_{\text {ad } v}$

We compare our $\theta_{\text {rec }}$ and $\theta_{a d v}$ with those from literatures, except for paraffin oil and 1-propanol that have liquid films. Other investigations directly measure advancing and receding angles using at least two liquids upon different surfaces $[23,40,43,45]$. The data are fitted by Eq. (10), as depicted in Fig. 8. Small values of $k$ are found in the experiments of Ramos and Tanguy [43], and Lam [40]. Solid surfaces are coated in their experiments to obtain small surface roughness. As listed in Table 5, the pristine surface in Ramos experiments has a root mean square roughness of $0.1 \mathrm{~nm}$, and the hysteresis is extremely small. After the pristine surface is decorated with hillocks, which is expected to raise the roughness, the coefficient $k$ rises from 0.09 to 0.14 . In Lam's experiments, the advancing and receding angles of different alkanes are measured on a silicon wafer coated with fluorocarbons. The roughness is claimed to be of nanometers. Morrow and Nguyen [23] claim to use roughened surface and their experiments are fitted with $k=0.78$, but they do not provide measured roughness. Meiron et al. [45] measure the advancing and receding angles of water and ethylene glycol on different surfaces with roughness (mean deviation of the vertical profile) of $1.3,9.3$ and $11.2 \mu \mathrm{m}$. Correspondingly, $k$ rises from 0.42 to 0.70 for the three surfaces.

Here we suppose that $k$ is positively correlated with the surface roughness. However, there are several parameters to quantify roughness, like the absolute average deviation of the peaks and

Table 4

The deviation of the advancing and receding angles from the static contact angle.

\begin{tabular}{|c|c|c|c|c|c|}
\hline Fluid & $\left|\frac{\theta_{a d v}-\theta_{0}}{\theta_{0}}\right|(\%)$ & $\left|\frac{\theta_{\text {rec }}-\theta_{0}}{\theta_{0}}\right|(\%)$ & RMSE (rad) & $B o\left(\times 10^{-4}\right)^{a}$ & Ca range \\
\hline Water & 0.2 & 40.7 & 0.05 & 0.36 & $8.1 \times 10^{-9}-3.5 \times 10^{-6}$ \\
\hline 1-propanol & 2.8 & 1.1 & 0.02 & 0.29 & $1.1 \times 10^{-8}-2.1 \times 10^{-5}$ \\
\hline $80 \% A G$ & 3.6 & 29.3 & 0.07 & 0.43 & $1.3 \times 10^{-6}-5.6 \times 10^{-5}$ \\
\hline $90 \% A G$ & 5.1 & 18.1 & 0.06 & 0.44 & $2.1 \times 10^{-6}-1.4 \times 10^{-4}$ \\
\hline Glycerol & 7.3 & 31.4 & 0.08 & 0.45 & $1.6 \times 10^{-6}-2.5 \times 10^{-3}$ \\
\hline DEG & 3.6 & 38.7 & 0.08 & 0.40 & $9.5 \times 10^{-8}-1.3 \times 10^{-4}$ \\
\hline TEG & 1.1 & 41.8 & 0.08 & 0.40 & $4.8 \times 10^{-7}-1.9 \times 10^{-4}$ \\
\hline PEG300 & 0.1 & 38.6 & 0.06 & 0.40 & $4.3 \times 10^{-7}-3.0 \times 10^{-4}$ \\
\hline Paraffin & 3.7 & 8.1 & 0.02 & 0.30 & $2.2 \times 10^{-7}-3.4 \times 10^{-5}$ \\
\hline PEG200 & 7.4 & 43.0 & 0.05 & 0.40 & $1.2 \times 10^{-7}-1.7 \times 10^{-4}$ \\
\hline PEG400 & 8.3 & 43.9 & 0.06 & 0.40 & $2.7 \times 10^{-7}-4.2 \times 10^{-4}$ \\
\hline PEG600 & 13.0 & 41.7 & 0.05 & 0.40 & $3.1 \times 10^{-7}-5.1 \times 10^{-4}$ \\
\hline
\end{tabular}

\footnotetext{
a Calculated by the hydraulic diameter of $80 \times 20 \mu \mathrm{m}$ tube, which is $16 \mu \mathrm{m}$.
} 


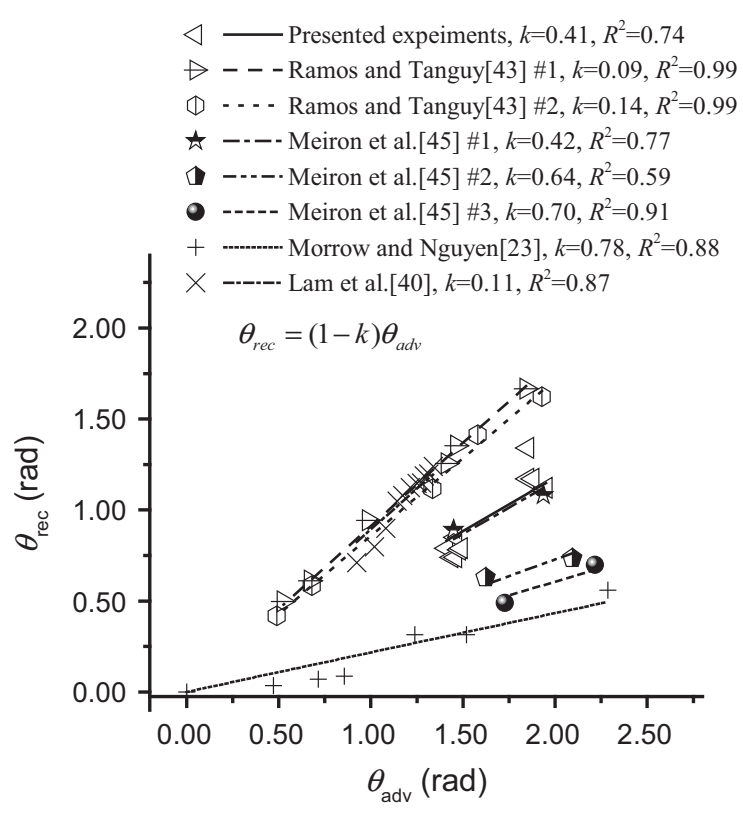

Fig. 8. The receding angle is a linear function of the advancing angle. The linear function $\theta_{\text {rec }}=(1-k) \theta_{a d v}$ is in good agreement with different experiments.

Table 5

Specifications of experiments used in Fig. 8.

\begin{tabular}{|c|c|c|c|}
\hline Reference & Surface treatment & roughness & $\begin{array}{l}\text { Fitting } \\
\text { results } \\
k\end{array}$ \\
\hline $\begin{array}{l}\text { Presented } \\
0.41\end{array}$ & experiments & None & $\sim$ \\
\hline $\begin{array}{l}\text { Ramos and } \\
\text { Tanguy } \\
\text { \#1 [43] }\end{array}$ & $\begin{array}{l}\text { Octadecyltrichlorosilane molecules } \\
\text { were grafted on the optical polished } \\
\text { surfaces of } \mathrm{LiNbO}_{3} \text { single crystals }\end{array}$ & $0.1 \mathrm{~nm}^{\mathrm{a}}$ & 0.09 \\
\hline $\begin{array}{l}\text { Ramos and } \\
\text { Tanguy } \\
\# 2[43]\end{array}$ & $\begin{array}{l}\text { Hillocks of a mean height of } 4.0 \pm 1.0 \\
\text { nm and a mean diameter } 17 \pm 2 \mathrm{~nm} \\
\text { were randomly distributed on the } \\
\text { processed surface. Hillocks } \\
\text { concentration was } 20 \mathrm{~cm}^{-2}\end{array}$ & $\sim$ & 0.14 \\
\hline $\begin{array}{l}\text { Meiron et al. } \\
\quad \# 1[45]\end{array}$ & Glass slide coated with beewax & $1.3 \mu \mathrm{m}^{\mathrm{b}}$ & 0.42 \\
\hline $\begin{array}{l}\text { Meiron et al. } \\
\quad \# 2[45]\end{array}$ & $\begin{array}{l}\text { Abrasive paper \#320 coated with } \\
\text { beewax }\end{array}$ & $9.3 \mu \mathrm{m}^{\mathrm{b}}$ & 0.64 \\
\hline $\begin{array}{l}\text { Meiron et al. } \\
\quad \text { \#3 [45] }\end{array}$ & $\begin{array}{l}\text { Abrasive paper \#240 coated with } \\
\text { beewax }\end{array}$ & $11.2 \mu \mathrm{m}^{\mathrm{b}}$ & 0.70 \\
\hline $\begin{array}{l}\text { Morrow and } \\
\text { Nguyen } \\
{[23]}\end{array}$ & none & $\sim$ & 0.78 \\
\hline $\begin{array}{l}\text { Lam et al. } \\
\quad[40]\end{array}$ & $\begin{array}{l}\text { Silicon wafer coated with } \\
\text { fluorocarbons }\end{array}$ & nanometers & 0.11 \\
\hline
\end{tabular}

a Root mean square roughness

b Arithmetical mean deviation of the vertical profile

valleys, the root mean square deviation from the mean elevation, etc. How to actually determine roughness based on these parameters and how other factors like defect concentration, defect spacing can influence the hysteresis remains to be further studied $[27,43,44]$. Contact angle hysteresis is still a unexplained phenomenon and more experiments are needed to quantify the relationship between $k$ and surface roughness.

In Fig. 8, most experiments utilize sessile drop method or plate immersion method. Although there is difference in test method, their data support the assumption or observation in this work: (i) the contact angle hysteresis vanishes when $\theta_{o}=0$; (ii) the linear relationship between $\theta_{\text {rec }}$ and $\theta_{\text {ad }}$ exists.

\subsubsection{An empirical form of the model}

It is noteworthy for nonwetting and slight-wetting liquids that the $\theta_{d}$ cannot be replaced by the $\theta_{o}$, because the receding deviation is significant, and the capillary force may also reverse its direction when the interface moves backward. It is appropriate to treat the $\theta_{a d v}$ and $\theta_{o}$ as the same, since the differences for most liquids are less than $10 \%$. Then Eq. (9) can be further developed into an empirical form of,

$\begin{cases}\theta_{d} \approx \theta_{o} & C a>0 \\ \theta_{d} \approx(1-k) \theta_{o} & C a<0\end{cases}$

Noted that $\theta_{o}$ is approximately equal to the $\theta_{a d v}$. With this model, the receding angle and hysteresis can be calculated for a given $\theta_{o}$ and $k$, after $k$ is fitted by several pairs of $\theta_{a d} v$ and $\theta_{\text {rec }}$ measured on the same surface by techniques like Wilhelmy method or tilting stage method [46].

\subsubsection{Capillary force in dynamic condition}

In a capillary, the contact angle indicates the direction of the capillary force. When $\theta_{a d v}>1.57 \mathrm{rad}\left(90^{\circ}\right)$, the capillary force is a resistance for advancing, otherwise it helps the liquid enter the capillary. When $\theta_{\text {rec }}<1.57 \mathrm{rad}$, the capillary force is a resistance for receding, otherwise it drives the liquid out of the capillary. On the basis of $\theta_{\text {rec }} \leqslant \theta_{a d v}$, the $\theta_{a d v}\left(\theta_{0}\right)$ and $\theta_{\text {rec }}$ of a wetting liquid both are less than $1.57 \mathrm{rad}$. Therefore, the capillary force of a wetting liquid assists the advancing but resists the receding. As for a nonwetting liquid, the $\theta_{a d v}\left(\theta_{o}\right)$ is larger than $1.57 \mathrm{rad}$, the capillary force resists the advancing.

In our experiments, the $\theta_{\text {rec }}$ of nonwetting liquids are less than $1.57 \mathrm{rad}$, but on a superhydrophobic surface the advancing and receding angles of water can be both larger than 1.57 rad [44]. Hence the capillary force could resist or drive the receding of nonwetting liquids. Calculation of the capillary force in dynamic condition using the static angle may induce errors or even predict a wrong direction.

\section{Conclusion}

With the excellence of pressure control and optical measurement, our experimental system overcomes the shortcomings of traditional capillary flow experiments where the contact angles can only be measured in capillaries with $1 \mathrm{~mm}$ diameter or above, or the capillary number cannot be controlled $[28,30]$.

It is confirmed by our experiments that the dynamic contact angle becomes independent of velocity with $10^{-9}<\mathrm{Ca}<10^{-5}$. Other types of experiments like sessile drop method, capillary rise or plate method also provide evidence of velocity-independence of the dynamic contact angle [22-25,47]. Though there are experiments coming to an opposite conclusion [13,17-21], two groups of experiments are executed mostly in different $\mathrm{Ca}$ regions. Together they disclose in what $\mathrm{Ca}$ regions the velocitydependence is significant or subtle. The viscous or velocity effect is more obvious in large $\mathrm{Ca}$ conditions. The cutting point of the independence is around $\mathrm{Ca}=10^{-5}-10^{-4}$, but a conservative estimate is $C a=10^{-5}$. The HD and MKT do not properly describe the $\theta_{d}$ in the mentioned range of $\mathrm{Ca}$ because unreasonable parameters are obtained. This is in agreement with Petrov's work, which reports the HD best fits the range of $\mathrm{Ca}>10^{-3}$, and the MKT fits around $\mathrm{Ca}=10^{-4}$ [13].

A velocity-independent model - the modified two-angle model as in Eq. (9) and a more empirical form Eq. (11) are proposed to replace the $\theta_{0}$ in dynamic conditions. The advancing angle was found to approximate the static contact angle, which is in consistency with the results from ref. [44]. We ascribe the coincidence to the measurement of $\theta_{0}$ by sessile drop method where a liquid 
drop has a tendency to spread (advance) due to gravity. Based on the equality of $\theta_{\text {adv }}$ and $\theta_{o}$, the model presumed that the $\theta_{\text {rec }}$ be a linear function of the $\theta_{a d v}$. Our experiments along with others' in ref. $[23,40,43,45]$ support the assumptions and follow the trend of Eq. (10). Further experimental proofs and theoretical development are needed for the whole region of $\theta_{a d v} \in[0, \pi]$.

Another finding is that the capillary force of a wetting liquid assists the advancing but resists the receding, and that of a nonwetting liquid resists advancing. The capillary force of a receding nonwetting liquid could possibly resist or assist the process depending on the $\theta_{\text {rec }}$. The modified two-angle model proposed in this paper could be reliable for the precise prediction of the capillary force in dynamic conditions.

\section{Acknowledgement}

This work was supported by the Strategic Priority Research Program of the Chinese Academy of Sciences (Grant No. XDA14010101), the National Natural Science Foundation of China (Grant No. 41690132), the National Program on Key Basic Research Project (973 Program, Grant No. 2014CB239004), the National Natural Science Foundation of China (Grant No. 41574129) and the Major National Science and Technology Special Program of China (Grant No. 2017ZX05037-001).

\section{Appendix A. Supplementary material}

Supplementary data associated with this article can be found, in the online version, at https://doi.org/10.1016/j.jcis.2018.02.074.

\section{References}

[1] M. Sohrabi, D.H. Tehrani, A. Danesh, G.D. Henderson, Visualization of oil recovery by water-alternating-gas injection using high-pressure micromodels, Spe J. 9 (3) (2004) 290-301.

[2] R. Bora, B.B. Maini, A. Chakma, Flow visualization studies of solution gas drive process in heavy oil reservoirs with a glass micromodel, Spe Reserv. Evaluat. Eng. 3 (3) (2000) 224-229.

[3] M. Piri, M.J. Blunt, Three-dimensional mixed-wet random pore-scale network modeling of two- and three-phase flow in porous media. I. Model description, Phys. Rev. E Stat. Nonlin Soft Matter. Phys. 71 (2 Pt 2) (2005) 026301.

[4] T. Lu, Z. Li, S. Li, P. Wang, Z. Wang, S. Liu, Enhanced heavy oil recovery after solution gas drive by water flooding, J. Petrol. Sci. Eng. 137 (2016) 113-124.

[5] R. Lenormand, C. Zarcone, A. Sarr, Mechanisms of the displacement of one fluid by another in a network of capillary ducts, J. Fluid Mech. 135 (1983) 337-353.

[6] M. Dong, F.A.L. Dullien, I. Chatzis, Imbibition of oil in film form over water present in edges of capillaries with an angular cross-section, J. Colloid Interface Sci. 172 (1) (1995) 21-36.

[7] A. Kantzas, I. Chatzis, F.A.L. Dullien, Mechanism of capillary displacement of residual oil by gravity assisted inert gas injection, Polski Przeglad Chirurgiczny 44 (7) (1988).

[8] M. Blunt, M.J. King, H. Scher, Simulation and theory of two-phase flow in porous media, Phys. Rev. A 46 (12) (1992) 7680-7699.

[9] M.J. Blunt, Flow in porous media - pore-network models and multiphase flow, Curr Opin Colloid In 6 (3) (2001) 197-207.

[10] A.Q. Raeini, B. Bijeljic, M.J. Blunt, Numerical modelling of sub-pore scale events in two-phase flow through porous media, Transp. Porous Media 101 (2) (2013) $191-213$.

[11] P. Meakin, A.M. Tartakovsky, Modeling and simulation of pore-scale multiphase fluid flow and reactive transport in fractured and porous media, Rev. Geophys. 47 (3) (2009).

[12] O.V. Voinov, Hydrodynamics of wetting, Fluid Dyn. 11 (5) (1976) 714-721.

[13] J.G. Petrov, J. Ralston, M. Schneemilch, R.A. Hayes, Dynamics of partial wetting and dewetting in well-defined systems, J Phys Chem B 107 (7) (2003) 16341645.

[14] C. Huh, L.E. Scriven, Hydrodynamic model of steady movement of a solid/ liquid/fluid contact line, J. Colloid Interface Sci. 35 (1) (1971) 85-101.

[15] T.D. Blake, The physics of moving wetting lines, J Colloid Interface Sci 299 (1) (2006) 1-13.

[16] T.D. Blake, J.M. Haynes, Kinetics of liquid/liquid displacement, J Colloid Interface Sci 30 (3) (1969) 421-423.
[17] M. Schneemilch, R.A. Hayes, J.G.P. And, †, J. Ralston, Dynamic Wetting and Dewetting of a Low-Energy Surface by Pure Liquids, Langmuir 14(14) (1998) 7047-7051.

[18] G. Ström, M. Fredriksson, P. Stenius, B. Radoev, Kinetics of steady-state wetting, J. Colloid Interface Sci. 134 (1) (1990) 107-116.

[19] W. Rose, R.W. Heins, Moving interfaces and contact angle rate-dependency, J Coll Sci Imp U Tok 17 (1) (1962) 39-48.

[20] R.L. Hoffman, A study of the advancing interface. I. Interface shape in liquidgas systems, J. Colloid Interface Sci. 50 (2) (1975) 228-241.

[21] J.-H. Kim, H.P. Kavehpour, J.P. Rothstein, Dynamic contact angle measurements on superhydrophobic surfaces, Phys. Fluids 27 (3) (2015) 032107.

[22] R.E. Johnson, R.H. Dettre, D.A. Brandreth, Dynamic contact angles and contact angle hysteresis, J. Colloid Interface Sci. 62 (2) (1977) 205-212.

[23] N.R. Morrow, M.D. Nguyen, Effect of interface velocity on dynamic contact angles at rough surfaces, J. Colloid Interface Sci. 89 (2) (1982) 523-531.

[24] D.Y. Kwok, A. Leung, C.N.C. Lam, A. Li, R. Wu, A.W. Neumann, Low-rate dynamic contact angles on poly(methyl methacrylate) and the determination of solid surface tensions, J. Colloid Interface Sci. 206 (1) (1998) 44-51.

[25] J.B. Cain, D.W. Francis, R.D. Venter, A.W. Neumann, Dynamic contact angles on smooth and rough surfaces, J. Colloid Interface Sci. 94 (1) (1983) 123-130.

[26] T.E. Mumley, C.J. Radke, M.C. Williams, Kinetics of liquid/liquid capillary rise : I. Experimental observations, J. Colloid Interface Sci. 109 (2) (1986) 413-425.

[27] M. Ramiasa, J. Ralston, R. Fetzer, R. Sedev, The influence of topography on dynamic wetting, Adv. Colloid Interface Sci. 206 (2014) 275-293.

[28] M. Fermigier, P. Jenffer, An experimental investigation of the dynamic contact angle in liquid-liquid systems, J. Colloid Interface Sci. 146 (1) (1991) 226-241.

[29] P. Wu, A. Nikolov, D. Wasan, Capillary dynamics driven by molecular selflayering, Adv. Colloid Interface Sci 243 (2017) 114-120.

[30] E. Schaffer, P.Z. Wong, Contact line dynamics near the pinning threshold: a capillary rise and fall experiment, Phys. Rev. EStatist. Phys. Plasmas Fluids Related Interdisciplinary Topics 61 (5A) (2000) 5257.

[31] P. Kunz, I.M. Zarikos, N.K. Karadimitriou, M. Huber, U. Nieken, S.M Hassanizadeh, Study of multi-phase flow in porous media: comparison of SPH simulations with micro-model experiments, Transp. Porous Media 114 (2) (2015) 581-600.

[32] N.K. Karadimitriou, M. Musterd, P.J. Kleingeld, M.T. Kreutzer, S.M. Hassanizadeh, V. Joekar-Niasar, On the fabrication of PDMS micromodels by rapid prototyping, and their use in two-phase flow studies, Water Resour. Res. 49 (4) (2013) 2056-2067.

[33] T. Gervais, J. El-Ali, A. Gunther, K.F. Jensen, Flow-induced deformation of shallow microfluidic channels, Lab Chip 6 (4) (2006) 500-507.

[34] J.N. Lee, C. Park, G.M. Whitesides, Solvent compatibility of poly (dimethylsiloxane)-based microfluidic devices, Anal. Chem. 75 (23) (2003) 6544-6554.

[35] J.B. Segur, H.E. Oberstar, Viscosity of glycerol and its aqueous solutions, Ind. Eng. Chem. 43 (9) (1950) 2117-2120.

[36] A. Pal, R. Gaba, Volumetric, acoustic, and viscometric studies of molecular interactions in binary mixtures of dipropylene glycol dimethyl ether with 1alkanols at $298.15 \mathrm{~K}, \mathrm{~J}$. Chem. Thermodyn. 40 (5) (2008) 818-828.

[37] S.X. Ma, G. Mason, N.R. Morrow, Effect of contact angle on drainage and imbibition in regular polygonal tubes, Colloid Surface A 117 (3) (1996) 273291.

[38] H.P. Kavehpour, B. Ovryn, G.H. McKinley, Microscopic and macroscopic structure of the precursor layer in spreading viscous drops, Phys Rev Lett 91 (19) (2003) 196104

[39] E. Atefi, J.A. Mann Jr., H. Tavana, A robust polynomial fitting approach for contact angle measurements, Langmuir 29 (19) (2013) 5677-5688.

[40] C.N.C. Lam, R. Wu, D. Li, M.L. Hair, A.W. Neumann, Study of the advancing and receding contact angles: liquid sorption as a cause of contact angle hysteresis, Adv. Colloid Interface Sci. 96 (1) (2002) 169-191.

[41] D. Bonn, J. Eggers, J. Indekeu, J. Meunier, E. Rolley, Wetting and spreading, Rev. Mod. Phys. 81 (2) (2009) 739-805.

[42] K. Grundke, K. Poschel, A. Synytska, R. Frenzel, A. Drechsler, M. Nitschke, A.L. Cordeiro, P. Uhlmann, P.B. Welzel, Experimental studies of contact angle hysteresis phenomena on polymer surfaces - Toward the understanding and control of wettability for different applications, Adv Colloid Interface Sci 222 (2015) 350-376.

[43] S. Ramos, A. Tanguy, Pinning-depinning of the contact line on nanorough surfaces, Eur Phys J E Soft Matter 19 (4) (2006) 433-440.

[44] Y.H. Yeong, A. Milionis, E. Loth, I.S. Bayer, Microscopic receding contact line dynamics on pillar and irregular superhydrophobic surfaces, Sci Rep 5 (2015) 8384.

[45] T.S. Meiron, A. Marmur, I.S. Saguy, Contact angle measurement on rough surfaces, J Colloid Interface Sci 274 (2) (2004) 637-644.

[46] L.M. Lander, L.M. Siewierski, W.J. Brittain, E.A. Vogler, A systematic comparison of contact angle methods, Langmuir 9 (8) (1993) 2237-2239.

[47] K. Grundke, D. Pospiech, W. Kollig, F. Simon, A. Janke, Wetting of heterogeneous surfaces of block copolymers containing fluorinated segments, Colloid Polym. Sci. 279 (8) (2001) 727-735. 